\title{
O MODELO DE CAPITALIZAÇÃO: UMA EXPERIÊNCIA DE MODELAGEM NO ENSINO MÉDIO
}

\author{
THE MODEL OF CAPITALIZATION: A MODELING EXPERIENCE IN \\ MIDDLE SCHOOL
}

Moisés Ceni de Almeida ${ }^{1}$

\begin{abstract}
Resumo: O presente artigo trata de um relato de experiência de uma oficina realizada com alunos do $3^{\circ}$ ano do Ensino Médio de uma escola estadual localizada no Rio de Janeiro/RJ. O fundamento teórico é baseado nos preceitos do ensino através da Modelagem Matemática e a metodologia é baseada nos casos de Modelagem Matemática da classificação de Barbosa $(2001,2004)$ e nos métodos de avaliação de Silva e Dalto (2017). O objetivo geral foi investigar e ampliar o saber dos alunos com relação ao Modelo de Capitalização como uma possível Previdência Complementar. O principal resultado foi constatar a relevância do debate e da formação da consciência cidadã através da Matemática e como a Modelagem pode contribuir para uma atividade de Matemática Financeira.
\end{abstract}

Palavras-chave: Educação Financeira; Capitalização; Modelagem Matemática.

Abstract: This article deals with an experience report of a workshop held with 3rd year high school students from a state school located in Rio de Janeiro / RJ. The theoretical foundation is based on the precepts of mathematics teaching through mathematical modeling and the methodology is based on Mathematical Modeling cases of Barbosa's classification. The general objective was to investigate and expand students' knowledge regarding the Capitalization Model, as well as a possible Complementary Pension Plan. The main result was to note the relevance of the debate and the formation of citizen consciousness through Mathematics and how Modeling can contribute to a Financial Mathematical activity.

Keywords: Financial Education; Capitalization; Mathematical Modeling.

\section{Introdução}

Este artigo constitui-se de um relato de experiência de uma oficina realizada com alunos de $3^{\circ}$ ano do Ensino Médio da Rede Pública Estadual do Rio de Janeiro. O título da oficina era: “O Modelo de Capitalização: Planejando para Toda a Vida!”. Essa oficina visou oferecer aos estudantes uma oportunidade de entender, através da Matemática, como o Modelo de Capitalização funciona, através de uma abordagem problematizadora.

O Modelo de Capitalização pode ser pensado como uma forma de investimento a longo prazo e é equivalente à uma previdência privada complementar ou a um Título de Capitalização. Atualmente, porém, países como Estados Unidos, Chile e Austrália

\footnotetext{
${ }^{1}$ Doutor em Engenharia Mecânica pela Universidade do Estado do Rio de Janeiro (UERJ). Professor do Departamento de Matemática e Desenho do Instituto de Aplicação Fernando Rodrigues da Silveira da Universidade do Estado do Rio de Janeiro (UERJ), Rio de Janeiro, RJ, Brasil. E-mail: moisesceni@gmail.com
} 
DOI: http://dx.doi.org/10.33238/ReBECEM.2019.v.3.n.2.22616

utilizam um Modelo de Capitalização em seus regimes previdenciários. Essa discussão tem sido apresentada na forma de uma nova proposta de regime previdenciário brasileiro (Brasil, 2019). Nesse contexto, cabe ao educador matemático se fazer a seguinte pergunta: Como nós e nossos alunos temos nos debruçado sobre esse tema, que pode interferir fortemente em nossas vidas pessoais?

Num relatório do Sistema de Proteção ao Crédito (SPC) e da Confederação Nacional de Dirigentes Lojistas (CNDL) realizado em 2018, constatou-se que apenas 1/3 dos entrevistados dos variados estados brasileiros costuma constituir alguma reserva em dinheiro e, além disso, 7 a cada 10 brasileiros preferem alocar suas reservas numa Caderneta de Poupança (SPC e CNLD, 2018). Esses dados, portanto, evidenciam a falta de discussão sobre a temática. Por isso, esperamos incentivar e promover a discussão sobre planejamento financeiro a longo prazo.

Sobre a problemática dos estudantes brasileiros quanto a educação financeira, Kioyosaki e Lechter (2000, p. 81) afirmam que:

Como os estudantes deixam a escola sem habilidades financeiras, milhões de pessoas instruídas obtêm sucesso em suas profissões, mas depois se deparam com dificuldades financeiras. Trabalham muito, mas não progridem. O que falta em sua educação não é saber como ganhar dinheiro, mas sim como gastálo (...). Essas pessoas muitas vezes trabalham mais do que seria necessário porque aprenderam a trabalhar arduamente, mas não como fazer o dinheiro trabalhar para elas.

A oficina deste relato de experiência visa principalmente a formação cidadã dos alunos quanto ao desafio de se planejar a longo prazo, a fim de perceber quais são os benefícios advindos desse planejamento e como este pode garantir uma situação financeira mais favorável com o passar dos anos.

A relevância de relacionar a Matemática com a formação cidadã do discente é tratada nos Parâmetros Curriculares Nacionais:

\footnotetext{
A Matemática é componente importante na construção da cidadania, na medida em que a sociedade se utiliza, cada vez mais, de conhecimentos científicos e recursos tecnológicos, dos quais os cidadãos devem se apropriar. A Matemática comporta um amplo campo de relações, regularidades e coerências que despertam a curiosidade e instigam a capacidade de generalizar, projetar, prever e abstrair, favorecendo a estruturação do pensamento e o desenvolvimento do raciocínio lógico. Faz parte da vida de todas as pessoas nas experiências mais simples como contar, comparar e operar sobre quantidades. Nos cálculos relativos a salários, pagamentos e consumo, na organização de atividades como agricultura e pesca, a Matemática se apresenta como um conhecimento de muita aplicabilidade. Também é um instrumental importante para diferentes áreas do conhecimento, por ser utilizada em estudos tanto ligados às ciências da natureza como às ciências sociais e por estar presente na composição musical, na coreografia, na arte e nos esportes. O papel que a Matemática desempenha na formação básica do cidadão brasileiro norteia estes Parâmetros (BRASIL, 1997, p. 19-27).
} 
Ainda quanto a temática da Matemática como propulsora da cidadania D’Ambrósio afirma que:

Cidadania tem tudo a ver com a capacidade de lidar com situações novas. Se lida com situações conhecidas e rotineiras a partir de regras que são memorizadas e obedecidas. Mas o grande desafio está em tomar decisões sobre situações imprevistas e inesperadas, que hoje são cada vez mais frequentes. A tomada de decisão exige criatividade e ética. A matemática é um instrumento importantíssimo para a tomada de decisões, pois apela para a criatividade. Ao mesmo tempo, a matemática fornece os instrumentos necessários para uma avaliação das consequências da decisão escolhida. A essência do comportamento ético resulta do conhecimento das consequências das decisões que tomamos (D'AMBRÓSIO, 2002, p.4).

A promoção da cidadania através da Matemática deve ser um dos objetivos centrais do professor que ensina Matemática. Para isso, o professor pode trazer discussões relacionadas ao contexto dos alunos e que promovam o senso crítico. Mais que isso, há o conhecimento matemático adquirido, que está relacionado ao problema posto em aula. Uma alternativa metodológica para esse objetivo é o uso de Modelagem Matemática.

Quanto ao uso de Modelagem Matemática em uma aula de Matemática, exige-se uma postura de "co-participante" para o professor. Nesse sentido, o professor, por sua experiência contribui na orientação e condução da aprendizagem. Essa tarefa é desafiadora é destacada na Literatura:

O ambiente de aprendizagem de Modelagem, baseado na indagação e
investigação, se diferencia da forma que o ensino tradicional - visivelmente
hegemônico nas escolas - busca estabelecer relações com outras áreas e o dia-
dia. Este último procura trazer situações idealizadas que podem ser diretamente
abordadas por idéias e algoritmos sugeridos pela exposição anterior do
professor. Os alunos, portanto, já sabem como proceder o que utilizar na
abordagem das situações (BARBOSA, 2001, p.8).

Essa postura "co-participante" do professor, portanto, se distancia do ensino tradicional e, no caso específico de matemática financeira, implica que a abordagem não poderá ser feita a partir de simples aplicações de fórmulas, mas sim de forma instigante e responsável, buscando sempre a reflexão dos resultados e dos procedimentos utilizados para alcança-los.

Com o intuito de auxiliar o desenvolvimento do aluno quanto a sua autonomia, as atividades de Modelagem podem contribuir quanto a reflexão dos dados e das metodologias aplicadas na resolução de uma situação-problema. Assim, o discente assume um papel de construtor e questionador do conhecimento. De acordo com Barbosa: "[...] as atividades de Modelagem podem contribuir para desafiar a ideologia da certeza e colocar lentes críticas sobre as aplicações da matemática (2004, p. 2)”. 
Por esses motivos, acreditamos que a relação binomial Educação Financeira $X$ Modelagem Matemática pode ser palatável e pode contribuir para uma formação matemática e cidadã do sujeito inserido na atividade.

$\mathrm{Na}$ seção 2, a seguir, apresentaremos a situação-problema central da oficina. $\mathrm{Na}$ seção 3 apresentaremos a metodologia utilizada para a confecção da oficina, a qual apresenta traços da Teoria de Biembengut e Hein (2000) e Barbosa (2001). Apresentamos também a metologia utilizada para a avaliação dos alunos, baseada na Teoria de Silva e Dato (2001).

\section{Sistema de Capitalização: Uma Abordagem Problematizadora}

A famosa fórmula dos Juros Compostos $V F=V P \cdot(1+i)^{t}$, aonde $V P$ corresponde ao Valor Presente, $i$ é a taxa em percentual, $t$ é o tempo e $V F$ é Valor Futuro, ocorrido pela atualização de VP pela taxa $i$ no tempo $t$, possui uma limitação importante: Considere a situação aonde você queira poupar e investir uma certa quantia $C$ todo mês, a uma taxa de $i \%$ ao mês. Qual será o valor futuro após um ano?

Para usarmos a fórmula dos Juros Compostos no caso acima, teremos de analisar mês após mês, já que o valor presente não é atualizado apenas pela taxa $i$, mas também pelos constantes investimentos somados todos os meses.

Tabela 1: Atualização dos valores

\begin{tabular}{cc}
\hline $\begin{array}{c}\text { Tempo } \\
\text { (meses) }\end{array}$ & Capital \\
Mês 0 & $C$ \\
Mês 1 & $C(1+i)+C$ \\
Mês 2 & $(C(1+i)+C)(1+i)+C$ \\
$\vdots$ & $=C(1+i)^{2}+C(1+i)+C$ \\
Mês 12 & \\
\end{tabular}

Fonte: Construção feita pelos alunos durante a oficina.

A oficina foi iniciada a partir dessa problemática: se pouparmos todo mês e investirmos esse valor durante um longo período de tempo, como poderemos determinar quanto teremos ao final do período? Outras perguntas também relevantes são: quanto esse montante ao final do período nos renderá ao mês? Esse valor vale o esforço de poupar? 


\section{Metodologia}

O uso de Modelagem Matemática auxilia na construção da aprendizagem e favorece o desenvolvimento de atividades baseadas em situações reais. Assim, o uso de Modelagem vai além de se alcançar uma fórmula que traduza a situação-problema, pois passa pelo refletir a própria situação real. Nesse sentido, Biembengut e Hein (2000) defendem que Modelagem Matemática é uma metodologia que envolve a aquisição de um modelo, mas que exige percepção e criatividade para explicar os contextos envolvidos.

Quanto a participação de professores e alunos em uma atividade de Modelagem Matemática, Barbosa (2001) classifica o uso de Modelagem Matemática em sala de aula em três casos:

Quadro 1: Caso de Modelagem Matemática em Sala de Aula

\begin{tabular}{|l|l|l|l|}
\hline & Caso 1 & Caso 2 & Caso 3 \\
\hline Elaboração da Situação-Problema & Professor & Professor & Professor/Aluno \\
\hline Simplificação & Professor & Professor/Aluno & Professor/Aluno \\
\hline Dados qualitativos e quantitativos & Professor & Professor/Aluno & Professor/Aluno \\
\hline Resolução & Professor/Aluno & Professor/Aluno & Professor/Aluno \\
\hline
\end{tabular}

Fonte: (BARBOSA, 2001 p. 9)

No primeiro caso, o professor exibe o problema e todos os dados necessários à resolução do problema, incluindo os dados matemáticos (como fórmulas, por exemplo) ou informações quantitativas (como tabelas, por exemplo). Nesse caso, o aluno participa apenas da etapa de resolução. Um exemplo desse caso pode ser a situação na qual o professor apresenta vários tipos de materiais que podem ser utilizados para a confecção de uma parede interna de uma casa, dadas as suas medidas. Essa atividade pode gerar uma bela discussão entre economia/durabilidade e, portanto, o custo-benefício da obra. No terceiro caso de Modelagem, os discentes participam desde a elaboração da situaçãoproblema, quanto das manipulações algébricas necessárias, da procura pelos dados necessários a resolução e da efetiva solução do problema proposto.

Nossa oficina se insere no caso 2, na qual a situação-problema é proposta pelo professor, mas todos os dados para a resolução do problema são buscados pelos discentes. Então, o problema era apresentado sob duas perguntas norteadoras:

- Como podemos determinar qual é o valor que teremos se aplicamos um valor $C$ todo mês durante um longo período de tempo a uma taxa $i$ ?

- Quais são as taxas praticadas hoje? Qual é valor que devemos poupar todo mês e qual será o nosso montante após 30 anos? 
DOI: http://dx.doi.org/10.33238/ReBECEM.2019.v.3.n.2.22616

Quanto a avaliação de cada fase do processo de Modelagem pelos diversos grupos, nós usaremos as escalas holísticas propostas por Silva e Dalto, 2017. Na primeira, atribuise em 0,1 ou 2 a percepção do discente quanto ao entendimento da situação-problema e da busca pelos dados necessários:

Quadro 2: Escala holística para a fase de inteiração

\begin{tabular}{|l|l|}
\hline \multicolumn{1}{|c|}{ Descrição da Situação-Problema } \\
\hline $\mathbf{2}$ & $\begin{array}{l}\text { É possível identificar a situação-problema; apresenta informações necessárias para a definição de } \\
\text { um problema a ser estudado. }\end{array}$ \\
\hline $\mathbf{1}$ & $\begin{array}{l}\text { É possível identificar a situação-problema, mas não apresenta informações necessárias para a } \\
\text { definição de um problema a ser estudado. }\end{array}$ \\
\hline $\mathbf{0}$ & Não é possível identificar a situação-problema. \\
\hline
\end{tabular}

\section{Fonte: (SILVA; DALTO, 2017 p. 9)}

Quanto ao quadro 2, nós vamos nos fixar quanto a busca dos alunos aos dados necessários para resolução da situação-problema, uma vez que nós a apresentamos.

A segunda fase é a de Matematização e Resolução e se refere ao momento em que os alunos vão procurar desenvolver o modelo matemático referente ao problema e simplificá-lo ao máximo possível para a tentativa de resolução. Nesse sentido, essa fase é avaliada sob dois aspectos: a dedução modelo e a resolução matemática. O que apresentamos a seguir é apenas parte da tabela original.

Quadro 3: Escala holística para a fase de Matematização

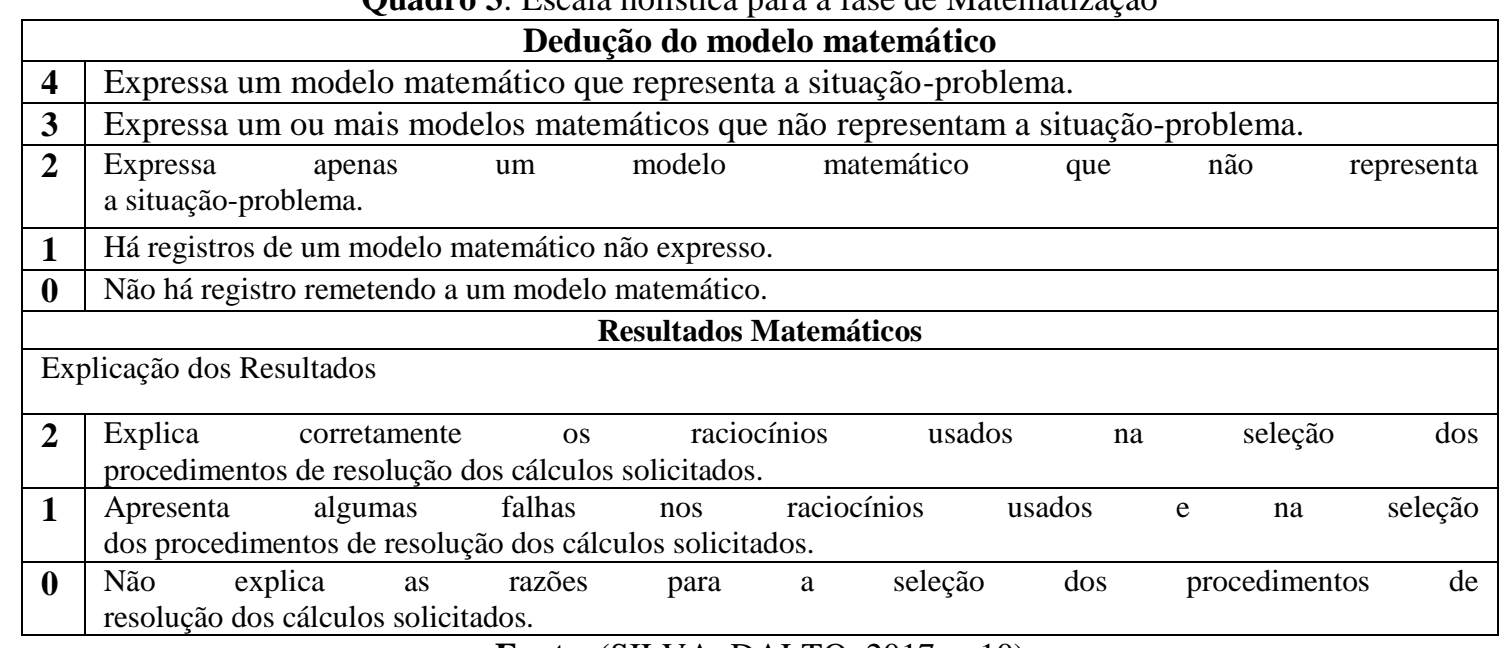

Fonte: (SILVA; DALTO, 2017 p. 10)

A terceira e última fase diagnóstica está relacionada com a habilidade de interpretar os resultados matemáticos, validar o resultado por meio de critérios bem estabelecidos e resolver o problema. A habilidade de validação é feita se o aluno explicita alguma comparação entre dados reais pesquisados ou não. A fim de avaliarmos essa habilidade nós pedimos aos estudantes fizessem testes com suas fórmulas, para períodos curtos feitos com a ajuda de um software de dados em tabela e em notícias de jornais. 
DOI: http://dx.doi.org/10.33238/ReBECEM.2019.v.3.n.2.22616

Quadro 4: Escala holística para a fase Resolução

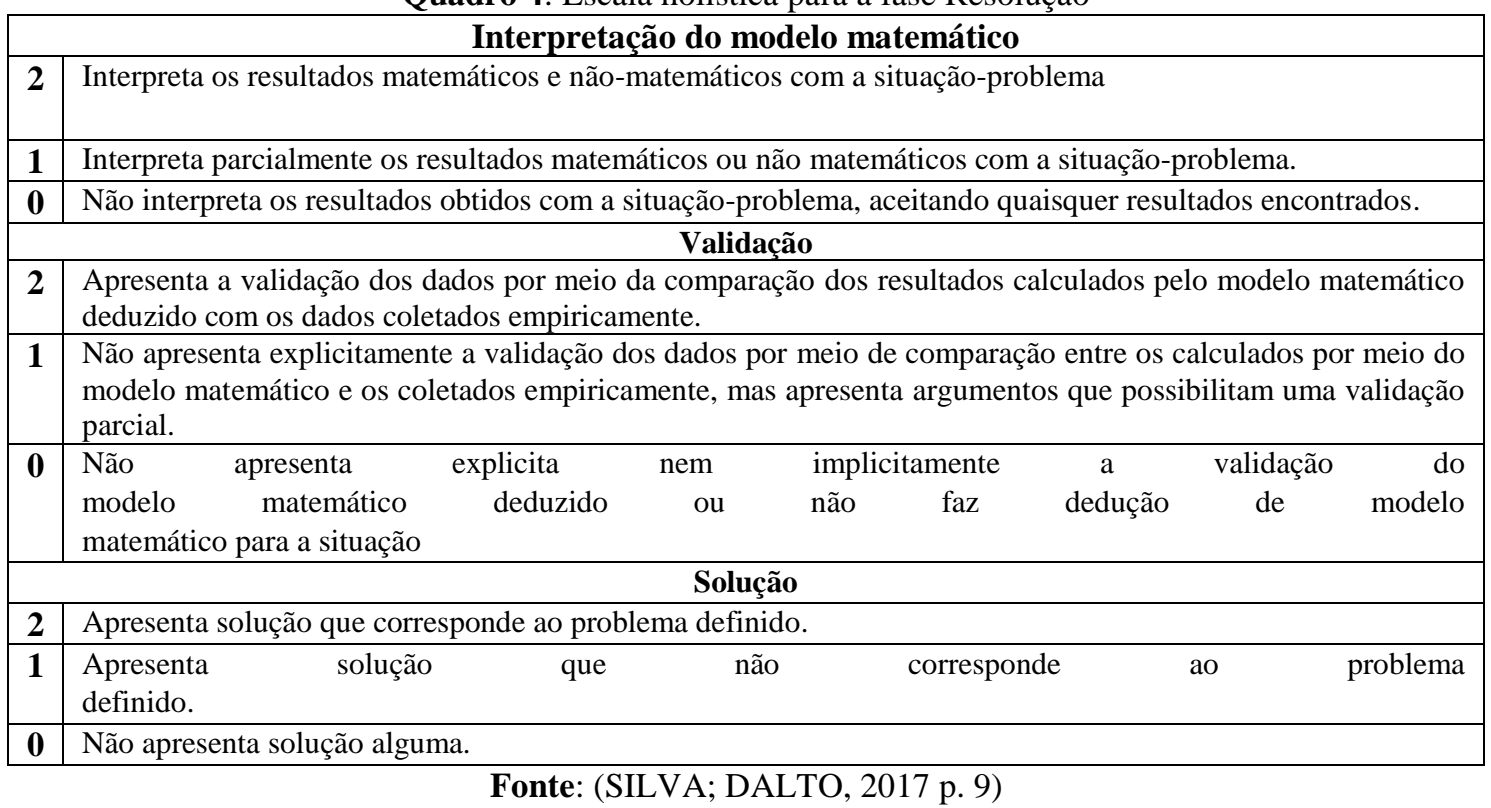

\section{A oficina: organograma e atividades}

$\mathrm{Na}$ aula que antecedia a Oficina, o professor orientador da atividade recomendava aos alunos que pesquisassem, individualmente, e trouxessem informações concretas sobre as seguintes questões norteadoras:

1. Como funciona um investimento bancário?

2. Quais são as taxas de retorno em investimentos como Poupança, CDB (Carta de Depósito Bancário), LCI (Letra de Crédito Imobiliário) e Previdência Privada (escolha um banco)? Há algum imposto sobre os lucros a pagar nesses investimentos? Escolha um ou mais investimentos para pesquisar!

No primeiro dia de atividades da oficina, em posse das informações, os alunos deveriam se organizar em grupo a fim de iniciarem as atividades. A primeira etapa consistiu numa discussão das informações encontradas pelos alunos e condensá-las numa resposta unificada para cada grupo:

1. Em grupo, definam, com suas palavras, o que é investimento bancário?

2. Quais são as taxas (ao ano) de retorno que vocês encontraram para os diversos tipos de investimento?

(a) Poupança:

(b) CDB:

(c) LCI:

(d) Previdência Privada: 


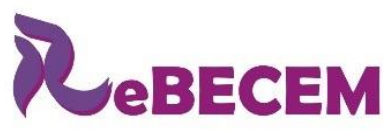

DOI: http://dx.doi.org/10.33238/ReBECEM.2019.v.3.n.2.22616

3. Quais tipos de investimentos pesquisados cobram impostos sobre os lucros?

4. Pelo que vocês puderam perceber, qual foi o investimento mais vantajoso se houver uma única aplicação por um tempo fixo? Faça alguns testes para comprovar o seu argumento.

$\mathrm{Na}$ última etapa do primeiro dia, os alunos novamente, eram convidados a realizarem pesquisa individualmente, em casa, sobre:

1. Qual é o salário médio de um brasileiro? E da classe média?

2. Qual é o percentual de salário que é aconselhável para quem deseja poupar?

No segundo e último dia de oficina, os alunos, coletivamente com a turma, discutiriam a prática de poupar a longo prazo. Por fim, nesse mesmo dia, os alunos fariam a matematização do problema e testes. Para orientá-los, eles deveriam responder as seguintes questões:

1. Construa um modelo matemático (fórmula) que sirva para determinar quanto teremos após economizarmos mês a mês, uma quantia fixa $\mathrm{C}$, a uma taxa de i\% ao mês, durante um período de um ano.

2. E após 360 meses? E após n meses?

3. Um valor de $\mathrm{R} \$ 1000$ aplicado todo mês durante 360 meses, aplicado a uma taxa de $1 \%$ ao mês, rende um valor de reais por mês.

4. Use um software de tabelas para verificar quanto renderia, mês a mês, uma aplicação mensal de $\mathrm{R} \$ 1000$, a uma taxa de $1 \%$ ao mês durante 6 meses. Esse valor confere com o resultado encontrado pela fórmula que vocês obtiveram na questão 2? Vocês conseguiram comparar a fórmula que vocês encontraram com alguma informação obtida pela pesquisa que vocês fizeram?

Por fim, os alunos relataram, individualmente, suas impressões sobre a oficina e eram convidados a realizarem mais pesquisas:

1. Quais países têm utilizado o sistema de capitalização como sistema vigente?

2. Essas experiências obtiveram sucesso em seus respectivos países? 


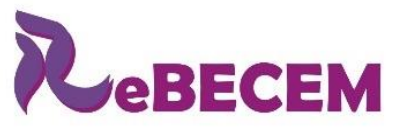

DOI: http://dx.doi.org/10.33238/ReBECEM.2019.v.3.n.2.22616

\section{0 relato dos alunos}

Na seção que se segue, transcreveremos integralmente as respostas recebidas por parte dos alunos. Usaremos nomes fictícios para nos referir aos alunos. Ao todo foram três grupos de oito alunos, totalizando 24 alunos.

No primeiro dia da oficina, as atividades estavam relacionadas à descrição da situação-problema, reconhecimento dos elementos matemáticos e não matemáticos em questão. Os elementos matemáticos se referem as descobertas de taxas reais e do comportamento o do dinheiro ao longo do tempo. Os elementos não matemáticos se referem ao conhecimento adquirido da discussão sobre como funciona um investimento financeiro e sobre a realidade social brasileira quanto a educação financeira.

Respostas dos grupos quanto a definir o que é um investimento financeiro. Grupo A:

"Nós acreditamos que investimento é quando você deixa um valor com o banco e depois pega de volta com juros".

Já o grupo B disse que investimento financeiro é:

“...um empréstimo que vocêfaz ao banco, que ele tem que devolver com juros”.

O grupo C definiu investimento financeiro como:

"Uma ótima maneira de economizar e garantir uma poupança no futuro".

Quanto as taxas, os três grupos puderam observar que as taxas variam com relação a vários fatores. Por isso, escolheram valores de taxa que pudessem representar os valores encontrados individualmente. Quanto ao que foi mais vantajoso, as respostas variaram. $\mathrm{O}$ grupo A apresentou a seguinte resposta:

"Consideramos no nosso cálculo que os três investimentos durariam 5 anos. Assim, podemos garantir que os investimos que possuem imposto de renda terão a menor taxa de todas. Colocamos um valor de $R \$ 10.000$ reais para investir.

Poupança: $10.000(1,0455)^{5}=12.491$.

CDB: $10.000(1,075)^{5}=14.356$. Tirando o imposto de renda: $14.356-$ $15 \%$ de $4.356=13.702$.

LCI: $10.000(1,067)^{5}=13.829$.

Previdência Privada: $10.000(1,073)^{5}=14.223$. Tirando o imposto de renda: $14223-15 \%$ de $4223=13589$.

A mais vantajosa foi o LCI!" 


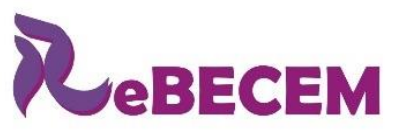

Revista Brasileira de Educação em

Ciências e Educação Matemática

DOI: http://dx.doi.org/10.33238/ReBECEM.2019.v.3.n.2.22616

Já o grupo B respondeu da seguinte maneira:

“O periodo escolhido para os testes foi de um ano. E o valor foi de $R \$ 2000$ reais. A poupança vai render 90 reais. $O C D B$ rende 140 e perde 24,50 de imposto, ficando em 115,50. Já o LCI renderá 114 reais. Como a previdência rende 146 reais menos os 25,55, teremos 120,45 reais. A mais vantajosa é a Previdência Privada."

O grupo C não considerou o valor de retirada pelo imposto de renda. Além disso, também precisou de ajuda quanto a escrever as taxas em forma decimal. A conclusão do grupo foi a de que o CDB deveria dar o maior retorno já que tinha a maior taxa.

Utilizando a Escala apresentada no Quadro 2, podemos observar que os grupos A e B, embora tenham apresentado respostas distintas, apresentaram todas as informações necessárias a solução da situação-problema real, numa perspectiva que leva em consideração os descontos que incidem sobre o ganho. Já o grupo C, embora tenha entendido o crescimento do capital ao longo do tempo, não apresentou todas as informações necessárias para resolução da situação-problema, pois não considerou os descontos por impostos. Porém, no momento de discussão com a turma, os alunos do grupo C puderam perceber a falha.

Durante a discussão feita em sala, os alunos expressaram verbalmente a relevância do estudo. Um aluno disse: "Entender como o mercado funciona nos ajuda em nossas vidas. É mais difícil de sermos enganados e podemos fazer planos para o futuro".

Quanto ao segundo dia de oficina, os alunos deveriam, com a ajuda do professor, tentar deduzir o modelo matemático que tratasse da situação-problema. Primeiramente, o professor sugeriu que os alunos fizessem mês a mês para tentarem observar um padrão. A fim de conquistarem esse objetivo, os alunos do grupo B montaram a tabela 1, da seção 2. Essa tabela foi socializada com a turma, após um período, com o objetivo de alcançar coletivamente a solução do problema.

Quanto a dedução do modelo, os três grupos observaram que a tabela resultava numa soma de uma Progressão Geométrica finita. Assim, os três grupos puderam encontrar a fórmula:

$$
M=\frac{C\left((1+i)^{\{n+1\}}-1\right)}{i}
$$

Portanto, os três grupos obtiveram conceito 4 na escala holística de dedução exibida no quadro 3 e conceito 2 na escala de explicação dos resultados. 


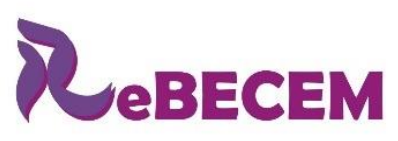

Revista Brasileira de Educação em

Ciências e Educação Matemática

DOI: http://dx.doi.org/10.33238/ReBECEM.2019.v.3.n.2.22616

Logo após os grupos obterem a fórmula para o montante, viria a fase de experimentação e validação do modelo matemático e dos elementos não matemáticos via uma discussão coletiva dos resultados.

Embora os três grupos tenham interpretado bem os seus resultados nãomatemáticos, como se pôde observar durante a discussão coletiva, o grupo A não conseguiu validar seus resultados. Quando tentaram encontrar o valor do montante encontrado pela economia de $\mathrm{R} \$ 1000$ reais por mês a uma taxa de $1 \%$ ao mês, pôde-se verificar que eles tentaram fazer manualmente, mês a mês e cometeram diversos erros de cálculo. Com isso, o valor encontrado pela fórmula não pôde se verificar.

Os três grupos obtiveram conceito 2 na escala holística de interpretação do Quadro 4. Já na validação, apenas o grupo A obteve o conceito 1, enquanto que os grupos B e C obtiveram conceito 2. Finalmente, os três grupos apresentaram uma solução efetiva para a situação-problema.

Abaixo, transcrevemos algumas respostas sobre as impressões individuais dos alunos quanto a oficina.

O Aluno E disse:

"A oficina agrega conhecimento para a vida futura, visto que ajuda no entendimento com dinheiro."

A aluna $\mathrm{S}$ respondeu:

"A oficina nos proporciona o aprofundamento em questões importantes, como encomia pessoal, e estimula a preocupação e cuidado com a vida financeira dos alunos."

Já a aluna L disse que:

"A oficina ensina novas formas de obter uma boa quantidade de dinheiro sem depender do estado."

$\mathrm{O}$ aluno Y disse:

"Nos mostrou o quanto podemos lucrar utilizando conhecimentos matemáticos." Por fim, o aluno $G$ disse:

"Ela agrega no meu futuro, quando eu possuir a minha renda própria e quiser investir dinheiro, nesse sentido a oficina foi útil para mim."

\section{Conclusão}

Esse artigo se propôs a relatar uma experiência no âmbito da Modelagem Matemática e da Educação Financeira realizada no formato de uma oficina com alunos 


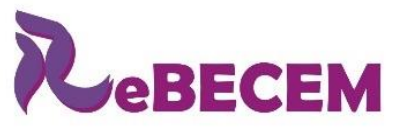

DOI: http://dx.doi.org/10.33238/ReBECEM.2019.v.3.n.2.22616
Revista Brasileira de Educação em

Ciências e Educação Matemática

ISSN 2594-9179

de uma escola pública do Estado do Rio de Janeiro. Nós pudemos observar que a estrutura problematizadora da oficina proporcionou ampla participação dos alunos quanto a tentativa de solucionar os problemas e uma grande participação nas discussões coletivas em sala de aula. Como um dos participantes diz: "pensar em como a sociedade brasileira lida com o dinheiro faz a gente pensar em como ainda não sabemos direito como usar matemática”.

A Modelagem da situação-problema enquanto metodologia se mostrou muito eficaz quanto ao desenvolvimento matemático e cidadão dos alunos, que puderam verificar como a Matemática escolar está fortemente relacionada com a realidade e, nem tão pouco, um conjunto de fórmulas que apenas alguns gênios podem apreciar. O sentimento vivido de criar Matemática, produzido pelos alunos (alguns pela primeira vez) se diferenciou de atividades tradicionalmente vividas na sala de aula de Matemática. Além disso, os mecanismos de verificação dos resultados encontrados aproximaram alunos e método científico. Esses mecanismos, que passaram pela utilização de Tecnologias Digitais, também ajudaram a articular o relacionamento entre Matemática e suas implicações reais.

Baseados na escala holística de Silva e Dalto (2017), nós pudemos observar que os alunos obtiveram sucesso na realização das atividades, o que é corroborado pelos relatos dos próprios alunos. Pontuamos que dois procedimentos foram essenciais para o sucesso do trabalho: o primeiro foi proporcionar a ampla participação dos alunos, como recomendado pela Literatura de Modelagem Matemática, que foi desde a obtenção dos dados necessários, como da geração de um modelo matemático que pudesse ajudar a responder os problemas com mais agilidade. Em segundo lugar, o trabalho coletivo proporcionou uma ampla discussão e contribuiu para que eventuais erros pudessem ser dirimidos. O sucesso dessa atividade não foi apenas no âmbito matemático, no sentido de se obter uma fórmula para resolver o problema, mas de promover o pensamento crítico e a formação cidadã do aluno, que foi empoderado pelo conhecimento adquirido.

Concluímos que essa oficina pôde mostrar para os alunos como a Matemática pode ser útil e relevante para suas formações enquanto cidadãos conscientes dos seus direitos e o que o uso de Modelagem Matemática enquanto metodologia numa atividade de Educação Financeira pode ser muito eficiente, desde que se definam critérios claros quanto a abordagem e avaliação dos procedimentos adotados. 


\section{Referências}

BARBOSA, J. C. Modelagem na Educação Matemática: Contribuições para o Debate Teórico. In: REUNIÃO ANUAL DA ANPED, 24., 2001, Caxambu. Anais... Rio Janeiro: ANPED, 2001. p. 1-30. CD-ROM.

BARBOSA, J. C. Modelagem Matemática: O que é? Por que? Como? Veritati, Salvador, v. 4, n.4, p. 73-80, 2004.

BRASIL. Secretaria de Educação Fundamental. Parâmetros Curriculares Nacionais: Matemática / Secretaria de Educação Fundamental. Brasília: MEC/SEF, 1997.

BRASIL. Reforma da Previdência: Apresentação da PEC. Ministério da Economia. Disponível em: http://sa.previdencia.gov.br/site/2019/02/2019-02-20_nova-previdencia_v2.pdf. Acesso em: 05 de maio. 2019.

BIEMBENGUT, M. S.; HEIN, N. Modelagem matemática no ensino. 5. ed. São Paulo: Contexto, 2000.

D’AMBRÓSIO, U. Que Matemática deve ser aprendida nas escolas hoje? Teleconferência no Programa PEC. Secretaria de Educação do Estado de São Paulo. Disponível em: https://drive.google.com/file/d/0B4JIJny_-_7paVFQdVY5aVI5YzA/view. Acesso em: 06 maio. 2019.

SILVA, K. A. P; DALTO, J. O. Uma Estratégia de Avaliação de Atividades de Modelagem Matemática. Revista Eletrónica de Investigación en Educación en Ciencias, Ciudad Autónoma de Buenos Aires, v. 12, n. 2, p. 1-17, dez. 2017.

SPC e CNLD. Cenário da Poupança e dos Investimentos Brasileiros. Disponível em: http://www.cvm.gov.br/export/sites/cvm/menu/investidor/estudos/pesquisas/20181002_estudo_ spc_cenario_da_poupanca_e_dos_investimentos_dos_brasileiros.pdf. Acesso em: 05 de maio. 2019.

KIOYOSAKI, R. T.; LECHTER, S. L. Pai Rico, pai pobre: O que os ricos ensinam a seus filhos sobre dinheiro. 66. ed. Rio de Janeiro: Elsevier, 2000.

Recebido em: 15 de junho de 2019.

Aceito em: 08 de agosto de 2019. 